\title{
ASBrS and ASO: A New Partnership Begins
}

\author{
Sheldon Feldman, MD, FACS ${ }^{1}$ and Funda Meric-Bernstam ${ }^{2}$ \\ ${ }^{1}$ Department of Surgery, Division of Breast Surgery, Columbia University College of Physicians and Surgeons, New York, \\ NY; ${ }^{2}$ University of Texas M. D. Anderson Cancer Center, Houston, TX
}

Welcome to the American Society of Breast Surgeons (ASBrS) inaugural issue of the Annals of Surgical Oncology (ASO), which, effective January 1, 2010, is the official journal of the ASBrS. The ASBrS was founded in 1995 by surgeons concerned about access to the latest breast technologies and quality of patient care. As the society has grown, its initiatives have expanded to include work in the areas of patient safety and quality, coding and reimbursement, certification, research, and education. ASBrS now has more than 2800 members in the United States and in 35 countries. The ASBrS is the primary leadership organization for surgeons who treat patients with breast disease, with membership inclusive of academia and community settings. It is committed to continually improving the practice of breast surgery by being an advocate for surgeons who seek excellence in the care of breast patients. This mission is accomplished by serving as a forum for the exchange of ideas and by promoting education, research, and the development of advanced surgical techniques.

This issue of the ASO highlights selected scientific content and educational material presented at our society's 11th annual meeting, which took place from April 28 to May 2, 2010, in Las Vegas. This meeting was attended by over 1300 physicians. The ASBrS Publications Committee reviewed 175 abstracts submitted, from which the best papers were selected for inclusion in this issue. The George Peters Award is given for the best paper by a fellow and was established by the society to honor Dr. George N. Peters, who was instrumental in bringing together the Susan G. Komen Breast Cancer Foundation, the ASBrS, the American Society of Breast Disease, and the Society of

(C) Society of Surgical Oncology 2010

S. Feldman, MD, FACS

e-mail: sf2388@columbia.edu
Surgical Oncology (SSO) to develop educational objectives for breast fellowships. ${ }^{1}$ The educational objectives were first used to award Komen Interdisciplinary Breast Fellowships. Subsequently, the curriculum was used for the breast fellowship credentialing process, which has led to the development of a nationwide matching program for breast fellowships. The Outstanding Scientific Award for the Best Paper by a Resident and Scientific Achievement are examples of the diverse high-quality educational material provided in this issue. ${ }^{2,3}$ Dr. Zannis's inspirational presidential address exemplifies the passionate leadership of the ASBrS, which continues on an upward trajectory. ${ }^{4}$ The initial experience with the Mastery of Surgery Program reported in this issue illustrates the tremendous commitment to defining quality measures that will raise the bar for the care for all breast patients. ${ }^{5}$

We are pleased with the wide variety of clinically relevant articles in this issue, including nipple-sparing mastectomy and oncoplastic surgical technique, partialbreast radiation methods, molecular pathology, breast magnetic resonance imaging, development of quality and outcomes measures, disparity in care, reconstructive surgery, tumor subtypes, new models for screening and diagnosis, breast conservation for multicentric disease, sentinel node biopsy, role of axillary node dissection, and an innovative intraoperative tumor localization method.

We want to acknowledge the vision and leadership of Suzanne Klimberg, Art Lerner, Charles Balch, and Jane Schuster (ASBrS), who have brought the ASBrS and the ASO together. This inaugural issue is the tangible result of their dedication to advancing education, research, and patient care. Special thanks to our highly committed ASBrS Publication Committee (Table 1) and to Laura Randel (ASBrS) and Deborah Whippen (SSO), who have worked in harmony to help produce this issue. We hope you enjoy reading it, and we encourage your further involvement in the ASBrS and ASO in the future. 
TABLE 1 American Society of Breast Surgeons Publications Committee Roster, 2010-2011

\begin{tabular}{ll}
\hline Chair & Sheldon M. Feldman, MD \\
\hline Members & Charles Balch, MD \\
& Paul L. Baron, MD \\
& Susan K. Boolbol, MD \\
& Judy C. Boughey, MD \\
& David R. Brenin, MD \\
& Anees B. Chagpar, MD \\
& Hiram S. Cody, MD \\
& Mehra Golshan, MD \\
& Tina J. Hieken MD \\
& Rosa Hwang, MD \\
& Kathie-Ann Joseph, MD \\
& Julian A. Kim, MD \\
& Sharon Lum, MD \\
& Jane Mendez, MD \\
& Funda Meric-Bernstam, MD \\
Barbara A. Pockaj, MD \\
Carol Scott-Conner, MD \\
Irene L. Wapnir, MD \\
Lee Wilke, MD \\
\end{tabular}

\section{REFERENCES}

1. Berry T, Brooks S, Sydow N, et al. Complication rates of radiation on tissue expander and autologous tissue breast reconstruction. Ann Surg Oncol. 2010;17.

2. Arora N, Tari King TA, Jacks LM, et al. The impact of breast density on the presenting features of malignancy. Ann Surg Oncol. 2010;17.

3. Beitsch P, Frank Vicini F, et al. 5-Year outcome in patients classified in the "unsuitable" category using the American Society of Therapeutic Radiology and Oncology (ASTRO) Consensus Panel (CP) guidelines for the application of accelerated partial breast irradiation (APBI): an analysis of patients treated on the American Society of Breast Surgeons (ASBS) MammoSite Registry Trial. Ann Surg Oncol. 2010;17.

4. Zannis V. Presidential address, 2010. The American Society of Breast Surgeons There's No "Boring" in Breast Surgery! Ann Surg Oncol. 2010;17.

5. Clifford EJ, De Vol EB, Pockaj BA, et al.: Early results from a novel quality outcomes program: the American Society of Breast Surgeons' Mastery of Breast Surgery. Ann Surg Oncol. 2010;17. 